\title{
Modelling non-linear Spatial Market Integration and Equilibrium Processes in Hidden Markov Framework
}

\author{
${ }^{*}$ Isaac Abunyuwah1, Edward E. Onumah ${ }^{2}$, Henry De-Graft Acquah ${ }^{3}$ \\ ${ }^{1}$ University of Education, Winneba, Ghana \\ 2University of Ghana, Legon- Ghana \\ ${ }^{3}$ University of Cape Coast Cape Coast, Ghana \\ *iabunyuwah@hotmail.com
}

\begin{abstract}
Along the basic rationale of the Enke-Samuelson-Takajama-Judge spatial equilibrium theory and the dynamic conceptualizations made from arbitrage processes, the study explores regime-switching techniques in hidden Markov framework. This is motivated by complex non-linear structure inherent in market integration processes, which is derived from multiple equilibria conditions, and transaction costs constrained threshold autoregressive (TAR) effects. These place theoretical limitations on current time series empirical models that are applied in market integration studies. In equilibrium representation, the non-linearities imposed by both alternating rent levels and switching adjustment parameters are directly accommodated. Two synthesized time series market data sets of varying levels of non-linear structures are used to highlight the strengths and limitations of the Markov variants vis-à-vis the band-TAR models that have currently dominated market integration analysis. The former model could capture alternating adjustment processes implied by the relatively complex non-linear market data set while the later produced mixed results.
\end{abstract}

Keywords: market integration, non-linear processes, threshold autoregression, multiple equilibria, Markov models

\section{Introduction}

In market integration (MI) modelling and analysis, three fundamental issues present challenges for parameter estimation and in effect complicate interpretation of empirical results. These are data availability and quality, theoretical and conceptual contextualisation, and as a result the choice for empirical model structure to be applied. For comprehensive MI studies data on transaction costs (TC), rent and trade series are very crucial in equilibrium representation. Basically, MI analysis attempts to identify the sequence and dynamics of inter-markets relationships as defined by the long-run equilibrium conditions on one level and arbitrage processes on the other. If all economic time series data of the markets are available or observable, one can easily conclude such patterns from data on transaction costs, trade quotas/volumes and price series as equilibrium theories postulate. That is, profit levels could easily be constructed to classify the markets into successful or failed arbitrage conditions as well as disintegrated/integrated outcomes given data on tradability.

As noted by Barrett (2005), at the heart of many spatial market integration analysis lies the EnkeSamuelson-Takajama-Judge (ESTJ) theory of spatial equilibrium. The concept in time space implies multiple equilibria system defined by prevailing arbitrage conditions and corresponding tradability structure (see Abunyuwah, 2008; Baulch, 1997; Sexton et al., 1991; Spiller and Wood, 1988 for conceptual review). This implicit long-run assumption has motivated the application of the parity bound model (PBM) as a regime-switching tool in MI analysis within equilibrium specification. In integrated markets, trade and arbitrage forces lead to price transmission and in effect rent adjustments conditional on prevailing transaction costs. That is in price transmission modelling transaction costs can constrain price adjustments and exhaustion of arbitrage opportunities to a given threshold. Under such conceptualisation, standard threshold autoregression (TAR) formulations have been utilised to analyse inter-market dynamics in a non-linear framework (see for example Balke and Fomby, 1997; Abdulai, 2002; Goodwin and Piggott, 2001; and recent applications by Butler and Moser, 2010; Fackler and Tastan, 2008; Moser et al., 2009; Stephens et al., 2008).

Notwithstanding the fact that insights from the PBM and TAR models raise important market policy, measurement and theoretical questions under specific inter-market conditions in their respective 
applications, they have not been combined effectively so far. Even though time series characteristics of markets inter-relationships carry important policy and methodological implications, they impose analytical complexity when other crucial elements of market integration concept such as transaction costs, arbitrage and spatial equilibrium conditions that play major role in PBM are to be directly reflected. Studies such as Abunyuwah (2008), van Campenhout (2009), Barrett and Li (2002) and Baulch (1997) have conceptually demonstrated how each of these and or their combined effects create non-linear constraints on the dynamic system. For instance, Abunyuwah $(2008,2013)$ demonstrates that if markets are characterised by switching equilibria conditions over time, then a two-layer non-linear structure ensues if transaction costs motivated threshold effect is present. The presence of the later characteristic leads to regime switching that is based on the level or magnitude of price differences in relation to prevailing TC. The former on the other hand results in non-linearity that alternates based on ruling equilibrium condition. Thus whether rent to arbitrage is equal, greater or less than zero at expectation $\left(E\left(R_{t}^{*}\right)=0, E\left(R_{t}^{*}\right)<0\right.$ or $E\left(R_{t}^{*}\right)>0$ ); where $R_{t}^{*}$ is rent, defined as price differences less transaction costs.

Indeed, identifying switching equilibria patterns over time under real dynamic, limited data and uncertain economic circumstances as is the case for agricultural commodity markets inter-relationships requires tools that can inherently infer latent structures from available observed variables. One of such tools is the hidden Markov model, which has been applied in varied forms and in different scientific domains. While few recent studies in MI analysis have utilised the Markov switching framework along Hamilton's (1989) specification (Zhao et al., 2012; Brummer et al., 2009; Kostov and Lingard, 2004), comprehensive investigation of the Markov switching structure with respect to data complexity that may be imposed by ESTJ spatial equilibrium theory and band-threshold (b-TAR) dynamics is limited. This paper contributes to the MI modelling literature by using synthesized market data of varying non-linear complexities to investigate the extent to which the Markov-switching framework can identify MI processes. The synthesized data sets are generated from existing MI model conceptualizations following Abunyuwah, (2008). We first apply the models when relatively simply non-linear inter-market processes that are motivated by transaction costs constrained threshold effects holds. In the other, we use relatively complex non-linear data structure that adds another level of non-linearity, which is derived from switching equilibria conditions to the former.

Methodological Developments in MI Analysis: Methodological concerns in MI analysis have retained consistent interest in the literature for over five decades now. The complexity of the MI concept has resulted in the application of varied models from different but consistent theoretical and or market and data structure contexts. In the dynamic framework for instance, time series tools of varying levels of structural complications have been applied under specific model assumptions to infer the extent and degree to which markets are integrated. These specifications have grown rapidly from simple bivariate correlation analysis of price series through asymmetric models, cointegration and error correction models (ECM) to threshold and other forms of non-linear methods. In the static framework however, MI analysis has been carried out within the structure of the ESTJ spatial equilibrium model.

Early modelling studies in MI analysis emerged in the early 1950s. In a static equilibrium setting, Enke (1951) defined trade functions and transportation costs for regions that trade in homogenous goods. In the system, each of the regions constitutes a single and distinct market separated but not isolated by transportation cost per unit. Under regional supply, demand and location price equilibrium conditions a state of equilibrium exists between these markets. Samuelson (1952) showed how this equilibrium process could be formulated into mathematical linear programming problem and demonstrated how its objective function could be solved by iterative methods. Takayama and Judge (1971) reformulated the problem into a quadratic programming setting. Notable applications and extensions in this modelling framework, which are popularly labelled Parity Bound Models (PBMs), include Baulch (1997), McNew \& Fackler (1997), Barrett \& Li (2002) and Negassa \& Myers (2007). As already noted by many previous studies, this framework provides comprehensive structure for MI analysis where issues of tradability, contestability, discontinuity in trade and market imperfections can be accommodated. Among major limitations raised against the PBM are data requirements (especially transactions cost and trade flow data), tractable model implementation procedures and model specification assumptions (Abunyuwah, 2012; van Campenhout, 2007 provide detailed review). 
In the dynamic framework, Farrell's (1952) empirical investigation on irreversible demand functions; Lele (1967), Granger \& Elliot (1967) and Tweeten \& Quance (1969) price-based assessment of markets can be considered as some of the earliest efforts to employing price transmission econometrics in market integration analysis. These early studies principally utilised price correlation on the premise that arbitrage processes of integrated markets will also have co-movement in their prices series. Ravallion (1986) then introduced a comprehensive and dynamic framework, which addressed many of the limitations that were raised against the simple bivariate correlation models. For instance, his model made provision for short and long run adjustment dynamics. In the late 1980s and early 1990s, insights from Granger causality tests, cointegration and error correction models, and their vector specifications brought considerable improvements in the time series framework (see for example, Brorsen et al., 1985; Kinnucan \& Forker, 1987; von Cramon-Taubadel, 1998; Wohlgenant, 1999). These in particular, addressed issues of non-stationarity and spurious parameter estimates.

Unlike studies in the static equilibrium specifications however, these models did not make provision for switching equilibria conditions or regime switching processes. To address non-linearity imposed by transactions cost on MI processes, the threshold models and extensions have been proposed and utilised extensively in the dynamic applications (For examples; Fackler and Goodwin 2001; Meyer 2004; Abdulai 2007; Fackler and Tastan 2008, Stephens et al., 2008; Moser et al., 2009; Butler and Moser, 2010). In fact, TAR models resolve one of the major modelling challenges in MI analysis. That is, they address non-linear constraint imposed on MI processes by transaction costs component without using observable transaction costs data. However, as noted above and recently demonstrated by Abunyuwah (2013) in synthesized experiment, the general b-TAR models do underestimate adjustment parameters when the DGP is characterised by switching equilibria dynamics. In their attempt to address switching inter-market adjustment processes in the time-series domain, Stephens et al. (2008) and Amikuzuno, (2011) utilised trade flow data in price transmission analysis, similar to tradability implications drawn from trade flow data in PBM applications. The current methodological frontier and empirical studies from both dynamic and static model applications point to non-linear complexities and challenges that confront analysts in MI studies. The continuous search for robust and yet flexible model structure in MI analysis is necessitated by market structure, efficiency, market imperfections and limited data implications that are derived from MI conclusions for market policy recommendations.

\section{Methodology}

Hidden Markov variants with dynamic adjustment techniques have seen dramatic applications in many economic fields since Hamilton's groundbreaking work in 1989 (see also Krolzig, 1997; Kim and Nelson, 1999 and Cappé et al., 2005). In fact, the HMM concept has been one of the most successful statistical tools utilised for complex patterns and systems analysis across almost all fields of scientific domain where interests had focused on sequence and systems identification, classification and dynamics over time. Classically, a hidden Markov model is doubly stochastic process with an underlying stochastic process that is not directly observable but can be observed only through another stochastic process that produces the sequence of observations (Cappé et al., 2005). Generally, depending on what one intends to model and the purpose for which the HMM is to be used, the process can be defined in terms of the joint probability distribution of the variables or through a functional representation, the so-called general state-space model.

In line with model structure used in the PBM framework for instance, we can assume that price differentials, $\left\{R_{1}, R_{2} \ldots \ldots R_{t}\right\}$ can be defined as independent series, given TC, but generated by a non-linear process defined by an $M$-state arbitrage conditions. In this case, the system can be thought of as having been generated from a multiple equilibria system with switching rent levels that are represented by $R_{t}^{*}=0, R_{t}^{*}<0$ or $R_{t}^{*}>0$, after taking transaction costs into account. From this scenario, regime one may imply equilibrium of normal economic profit $R_{t}^{*}=0$ (rent to arbitrage is zero), while in regime two the cost of trade might be unduly high to imply autarky condition (i.e. price differentials fall far below the implied transactions cost). Regime three which refers to periods of arbitrage failure may be due to say trade barriers or market power (i.e. price differentials fall far above the implied transactions cost). This position can be seen as direct representation of the PBM in a hidden Markov sense. To reflect the market dynamics in MI analysis as those in b-TAR models, a functional representation, the Markov switching model is applied. 
Noting that hidden Markov model is doubly stochastic process with the state variable not directly observable but produces the sequence of the observations variable, the two doubly stochastic processes can be expressed and defined as stated in equations (01) to (04) based on joint and conditional probability theory.

$$
\begin{aligned}
& P\left(R_{t: T}, C_{t: T}\right)=P\left(R_{T}, C_{T} \mid R_{1: T-1}, C_{1: T-1}\right) P\left(R_{1: T-1}, C_{1: T-1}\right) \\
& =P\left(R_{T} \mid C_{T}, R_{1: T-1}, C_{1: T-1}\right) P\left(C_{T} \mid R_{1: T-1}, C_{1: T-1}\right) P\left(R_{1: T-1}, C_{1: T-1}\right) \quad \ldots \ldots . . .(2)
\end{aligned}
$$

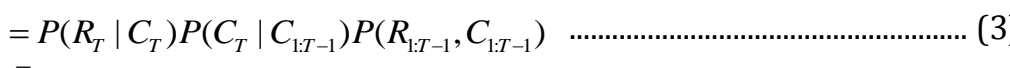

$$
\begin{aligned}
& =P\left(c_{1}\right) \prod_{t=2}^{T} \underbrace{P\left(C_{t} \mid C_{t-1}\right)}_{a_{i j}=A} \prod_{t=1}^{T} \overbrace{P\left(R_{t} \mid C_{t}\right)}^{b_{j}\left(R_{t}\right)}
\end{aligned}
$$

Where, $P\left(c_{1}\right)=\pi_{i}$, is the initial state; $P\left(C_{t} \mid C_{t-1}\right)=a_{i j}=A$, is state transition probabilities; $P\left(R_{t} \mid C_{t}\right)=b_{j}\left(R_{t}\right)$, is observed probabilities of the $R_{t}$ series given the hidden state processes (see Kim and Nelson, 1999; Cappe et al., 2005; Blimes, 2006 for detailed exposition).

When a given system can be modelled in HMM then both the observation sequence and the underlying state sequence probabilities can be calculated from the conditional dependencies among the variables given the model parameters. The above frame of estimation, fundamentally defines the statistical estimation tool for HMMs. However, specific computational complexities arise as to what distributional, stability of the transitional states and or dynamic structural assumptions one imposes on the system. For instance, in state-space models of many applied economics analysis the forward/backward probabilities are evaluated via Hamilton (1989) and or Kim (1994) filters. Applications of Markovian approaches in econometrics have been generally based on the Markov regime switching of Hamilton (1989), which in general moves along the switching linear Gaussian autoregression models. Other prominent applications in econometrics include Hamilton and Susmel (1994), Filardo (1994), Diebold et al. (1994), Krolzig (1997), Kim and Nelson (1999), Krolzig et al. (2002) and Otranto (2005). In these extensions assumptions underlying the transition probability, lag-structure and variance component among others have been relaxed and/or expanded based on theoretical basis of the context in which the data generating processes (DGP) are assumed.

Markov-Switching Market Equilibrium Model: As noted above, Markov switching models are special form of classical HMMs where the observed series do not only depend on the state variable but also on some lag variables. Based on ESTJ equilibrium theory and TAR models, with relatively high frequency data, the $R_{t}$ series is specified to account for any dynamic adjustments that govern each of the equilibrium points. If data on trade is available, as sometimes used in the PBM structure, then two lines of specifications are possible in the vector framework; by assuming co-breaking of state processes for system variables in one case and relaxing the assumption of co-breaking in the other (see Otranto, 2005). Since the two differ by inter-state dependence structure and computational complexities, we implement the models that carry the co-breaking assumption in this demonstration. In equation (06) the system is specified in dynamic framework to account for rent adjustments as those evaluated in classical threshold autoregressive settings of (05) but with the possibility of accounting for switching system parameters that may be imposed by market segmentation, threshold effects and or market imperfections.

$$
\begin{aligned}
& R_{t}=\beta R_{t-1}+u_{t} \\
& \text { (5) } \\
& P\left(R_{t} \mid R_{t-1}, C_{m}\right)=\left\{\begin{array}{cl}
f\left(R_{t} \mid R_{t-1}, \Phi_{1}\right) & \text { if } c_{m}=1 \\
\cdot & \\
f\left(R_{t} \mid R_{t-1}, \Phi_{M}\right) & \text { if } c_{m}=M
\end{array}\right.
\end{aligned}
$$

The state variable $c_{m}$ of equation (06) indicates one of the M possible market equilibria (regimes) that govern the system at time t. In general, the $\boldsymbol{R}_{t-1}$ vector represents the observations $\left\{R_{t-j}\right\}_{j=1}^{\infty}$ in the vector autoregression system and the parameter vector $\Phi$ is assumed to be dependent on the ruling state at time t. As shown in Krolzig (1997), a classical threshold representation and equilibrium TAR in particular reduces to two-state switching autoregressive model as stated in equation (08) below. The switching 
coefficients represent two alternating adjustment parameters that characterise the process dynamics when $R_{t-1}$ exceeds TC on one hand, and for when $R_{t-1}$ is lower than TC. The band-threshold autoregressive (b-TAR) models of price differentials, which are often used in the analyses of the law of one price and other arbitrage-based models in market integration analysis (see Obstfeld and Taylor, 1997) can be deduced from standard autoregressive model (05) as follows:

$$
\begin{array}{r}
\Delta R_{t}= \begin{cases}\rho_{1}\left(R_{t-1}-\tau_{1}\right)+e_{1} & \text { if } \infty>R_{t-1} \geq \tau_{1} \\
\rho_{0} R_{t-1}+e_{2} & \text { if } \tau_{1}>R_{t-1}>\tau_{2} \\
\rho_{1}\left(R_{t-1}+\tau_{2}\right)+e_{3} & \text { if } \tau_{2} \geq R_{t-1}>-\infty\end{cases} \\
\Delta R_{t}=\delta_{C m}+\rho_{C m} R_{t-1}+e_{t}
\end{array}
$$

For general b-TAR framework however, three-state mean/intercept model with two statistically distinct switching adjustment parameters ( $\rho_{0}$ and $\rho_{1}$ as in equation (07)) that associate dynamics within and outside the threshold band respectively apply. This can be seen from the b-TAR representation in (07) above, where in a symmetric structure the mean values for regime 1 and 3 differ by their signs. In equation (08), $\rho_{\mathcal{C}_{m}}$ represents the degree to which deviations from the TC $\left(\tau_{i}\right)$ are corrected, a form of "error-correction"; $\delta_{C_{m}}$ captures state-specific intercept/mean and $e_{t}$ is the error term.

From the perspective of PBM as a mixture distribution model where three differing rent levels may alternate in the long run, the non-linear structure imposed by b-TAR as discussed above is altered. Thus, after accounting for persistent adjustment processes imposed by TC within the threshold band, the system may still exhibit some adjustment persistence as propagated by periods of inter-markets segmentation states. In the general PBM structure of equation (09) below, TC data is used to construct the rent series by defining the upper and lower bounds.

$$
\begin{aligned}
L & =\prod_{t=1}^{T}\left[\lambda_{1} f_{t}^{1}+\lambda_{2} f_{t}^{2}+\left(1-\lambda_{1}-\lambda_{2}\right) f_{t}^{3}\right] \\
f_{t}^{1} & =\frac{1}{\sigma_{v}} \phi\left[\frac{R_{t}^{*}-\alpha}{\sigma_{v}}\right] \\
f_{t}^{2} & =\left[\frac{2}{\left(\sigma_{u}^{2}+\sigma_{v}^{2}\right)^{1 / 2}}\right] \phi\left[\frac{R_{t}^{*}-\alpha}{\left(\sigma_{u}^{2}+\sigma_{v}^{2}\right)^{1 / 2}}\right] \times\left[1-\Phi\left[\frac{-\left(R_{t}^{*}-\alpha\right)^{\sigma_{u}} / \sigma_{v}}{\left(\sigma_{u}^{2}+\sigma_{v}^{2}\right)^{1 / 2}}\right]\right] \\
f_{t}^{3} & =\left[\frac{2}{\left(\sigma_{u}^{2}+\sigma_{v}^{2}\right)^{1 / 2}}\right] \phi\left[\frac{R_{t}^{*}-\alpha}{\left(\sigma_{u}^{2}+\sigma_{v}^{2}\right)^{1 / 2}}\right] \times\left[1-\Phi\left[\frac{\left(R_{t}^{*}-\alpha\right)^{\sigma_{u}} / \sigma_{v}}{\left(\sigma_{u}^{2}+\sigma_{v}^{2}\right)^{\frac{1 / 2}{2}}}\right]\right] \\
R_{t}^{*} & =u_{t}+\delta_{C_{m}}
\end{aligned}
$$

In equation (09) the $\lambda_{k}$ are probabilities, describing the three regimes and the error parameters are defined by $\alpha, \sigma_{\mathrm{u}}^{2}$ and $\sigma_{\mathrm{v}}^{2}$. From equation (10), $\phi$ is the standard normal density function and $\Phi$ is the standard cumulative distribution function (see Barrett \& Li, 2002 for comprehensive model with trade flow data). We state the Markovian version of the PBM in equation (11), where $R_{t}^{*}$ of the equation defines $T \times N$ observed series ( $N=1$ in present case with rent series only, no trade variable considered; and $T$ is the length of the series). In this case, rent equals price differentials less TC. The $\delta_{C_{m}}$ comprises of the state-dependent equilibrium rent levels, (e.g. $R^{*}=0$, under perfect integration case for rent) and error term, $u_{t}$ which follows normal i.i.d (the variance can also be allowed to vary across regimes). Under conditions where $c_{m}$ does imply that $R \neq 0$, then $\delta_{C_{m}}$ switches between significantly positive or negative mean to represent periods of inter-market segmentation or imperfections. While under the PBM 
$\delta_{C_{m}}$ is inherent component of the error term, $u_{t}$ (i.e. the normal plus half-normal components), under MS-EM as stated above, it implies state-specific mean/intercept, which propagates on a hidden stochastic process over time (see Abunyuwah, 2008 for comprehensive demonstration under different assumption).

Demonstration with Synthesized Data: Two different series with differing non-linear complexities are used in this experiment. Based on the ESTJ theoretical framework and PBM in particular, price differentials are generated directly. The process of integration is taken into account by using b-TAR framework as specified in equation (07), which translates into equation (08) above. The first set comes from a purely transaction costs (TC) based TAR propagated data generating process (DGP) as in equation (07) while the other adds another layer of non-linear complexity imposed by inter-market segmentation or imperfections as implied by PBM set up of equation (09).

The first set was utilized to highlight the strengths of the TAR and MS-EM models when the non-linear complexity is imposed by transaction costs on the adjustment process in the inter-market relationship only. The resultant series is denoted as series $A$, where $\rho_{1}=-0.78$ at expectation, ( $\left.\beta_{1}=0.22\right)$ and $\rho_{0}$ set at zero ( 0 ) at expectation (thus, $\beta_{0}=1$ ), which defines random walk process within the threshold band. We also set TC and threshold parameter, $\tau_{1}=\tau_{2}=5.0$, indicating symmetric structure; with 1.20 innovation $(u)$ variance component. This is presented in figure 1 below as simple non-linear series. Here, when tradability holds any significant margin that emerges is quickly exhausted and as such price differentials revert to TC $(\tau)$ bounds. To exemplify the real strengths and limits of these models we have concentrated on the dynamics that associate with inter-markets equilibrium processes as dictated by various levels of market efficiency or inefficiency. In effect, the complexity that a trend component in the time series can impose on TAR modeling, especially on transactions cost (see van Campenhout, 2007) and the latter's non-constant implications, are not included in this demonstration. This was done to avoid dampening the strengths of classical TAR models in identifying transaction costs motivated threshold effects.

Figure 1: Simple Non-linear Price Differentials Series (Series A)

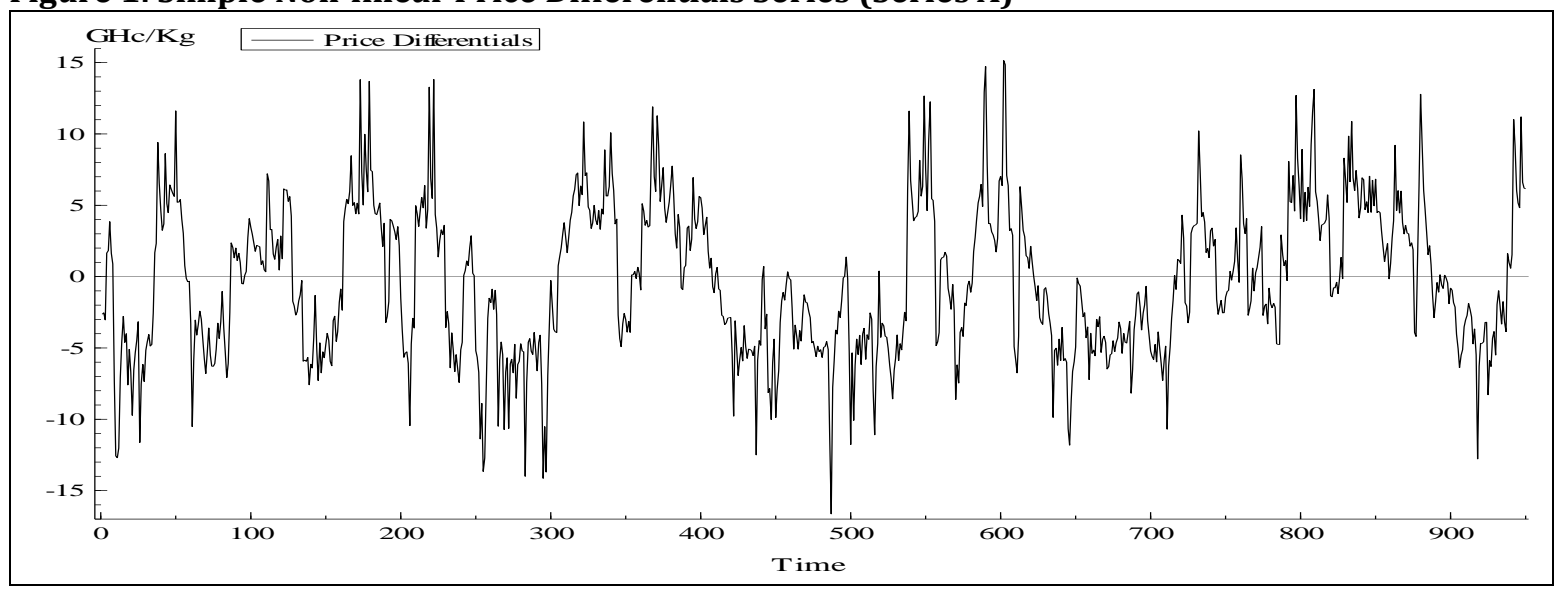

Source: Authors' own construct

In the second data set relatively complex non-linear processes that accommodate switches between intermarkets conditions within multiple equilibria structure as implied by the PBM, specification in equation (09) above is used. This series is shown in Figure 2 below and denoted as series $B$. As in the simple nonlinear set above, $\rho_{1}$ was set to negative 0.78 (beta $=0.22$ ) for tradability periods beyond the threshold point of 5.0 with normally distributed errors with variance 1.2. In addition 2 periods of stylised imperfect/segmented market conditions were fixed around time points (71:115 and 621:675). In these periods $\rho_{i}=0$ was implied to reflect inter-market segmentation periods. Again, we did not include trend and non-constant TC in the series for reasons noted above. 


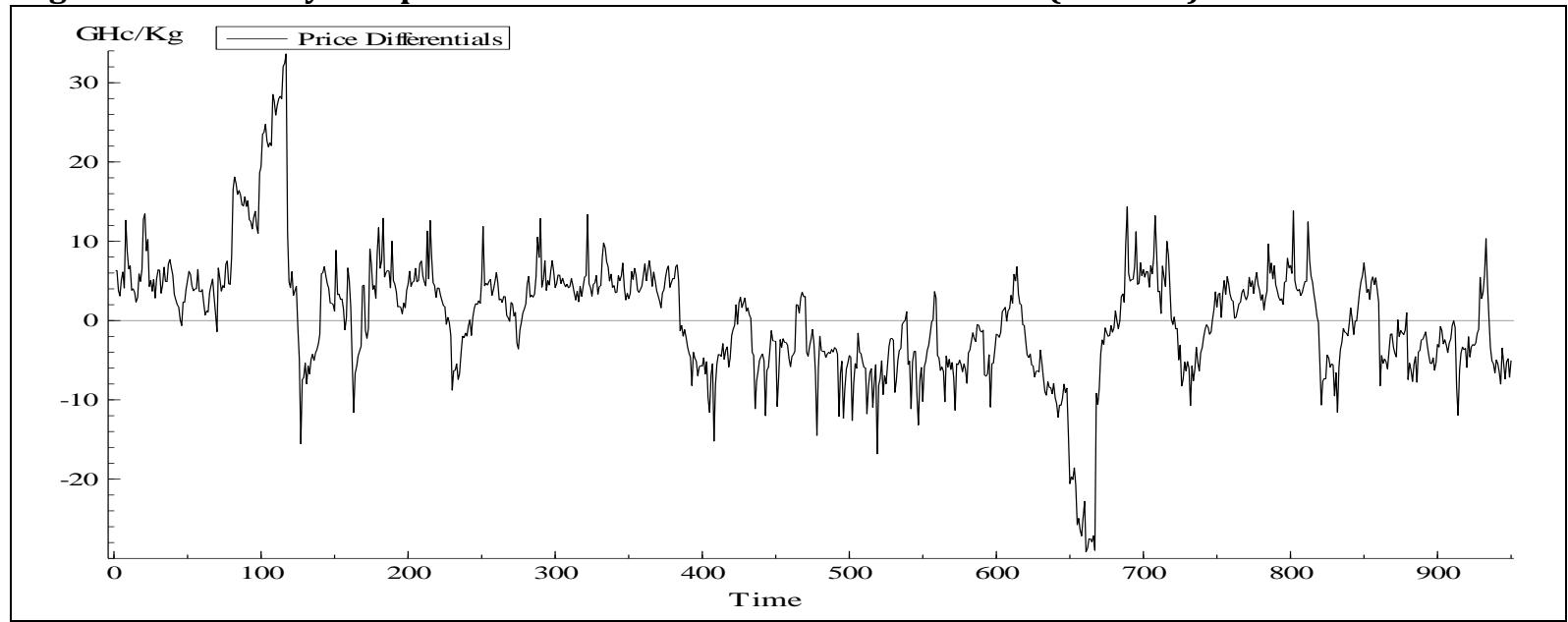

Source: Authors' own construct

\section{Results}

Results from Band-Tar and Markovian Models: In Table 1 below, b-TAR model is used to analyse series $A$ presented above to conclude on the implied inter-market processes by assuming that the DGP is of TC constrained threshold type. In effect it is expected that rho $\left(\rho_{0}\right)$ from equation (07 and 08) should not differ significantly from zero to reflect random walk nature of price differentials that fall within the threshold band. However, rho $\left(\rho_{1}\right)$ should significantly differ from zero to correspond to periods in which price differentials exceeded TC levels in absolute terms. We utilise general SETAR set up with the Markov-switching package (MSVAR) of Krolzig (1998) on OX 3.2 platform and Gauss codes provided by Kim \& Nelson (1999).

Table 1: TAR and Markov Analysis for Simple Non-linear Relations (Series A)

\begin{tabular}{|c|c|c|c|c|c|c|c|}
\hline \multirow[b]{2}{*}{ Variable } & \multirow{2}{*}{$\begin{array}{l}\text { Linear } \\
\text { Model }\end{array}$} & \multirow[b]{2}{*}{$\begin{array}{l}\text { Regime } \\
1\end{array}$} & \multicolumn{2}{|c|}{ B-TAR Model } & \multicolumn{3}{|c|}{ Markov Variant (MSIA) } \\
\hline & & & Regime 2 & $\begin{array}{l}\text { Regime } \\
3\end{array}$ & Regime 1 & $\begin{array}{l}\text { Regime } \\
2\end{array}$ & $\begin{array}{l}\text { Regime } \\
3\end{array}$ \\
\hline $\begin{array}{l}\text { Threshold } \\
\text { Point }\end{array}$ & & $\mathrm{Rt} \leq-4.84$ & $\begin{array}{l}-4.84 \leq \mathrm{Rt} \leq \\
4.38\end{array}$ & $\mathrm{Rt} \geq 4.38$ & & & \\
\hline Constant & $\begin{array}{l}-0.103 \\
(0.082)\end{array}$ & $\begin{array}{l}-3.574 \\
(0.538)\end{array}$ & $\begin{array}{l}-0.103 \\
(0.105)\end{array}$ & $\begin{array}{l}4.696 \\
(0.545)\end{array}$ & $\begin{array}{l}-2.731 \\
(0.346)\end{array}$ & $\begin{array}{l}0.124 \\
(0.073)\end{array}$ & $\begin{array}{c}1.420 \\
(0.384)\end{array}$ \\
\hline $\mathrm{R}(\mathrm{t}-1)$ & $\begin{array}{l}-0.149 \\
(0.017)\end{array}$ & $\begin{array}{l}-0.619 \\
(0.074)\end{array}$ & $\begin{array}{l}-0.066 \\
(0.036)\end{array}$ & $\begin{array}{l}-0.754 \\
(0.075)\end{array}$ & $\begin{array}{c}0.799 \\
(0.072)\end{array}$ & $\begin{array}{l}-0.085 \\
(0.017)\end{array}$ & $\begin{array}{l}-0.818 \\
(0.084)\end{array}$ \\
\hline $\begin{array}{l}\text { Regime } \\
\text { Probabilities }\end{array}$ & 1.0000 & 0.215 & 0.579 & 0.207 & 0.079 & 0.819 & 0.109 \\
\hline LR (Davies) & & & $831(0.000$ & & & & \\
\hline
\end{tabular}

Source: Own Analysis with MSVAR 3.1: ${ }^{* * * * * *}$, ; represent significance levels under 1, 5 and 10\%

As expected, the test for the presence of threshold effects against the null of linear representation strongly favours the former as indicated by the likelihood ratio (LR) statistic and highly significant pvalue for Davies statistic. The estimated values for rho $\left(\rho_{1}\right.$ and $\left.\rho_{0}\right)$ strongly point to rapid adjustment process that characterises the series when the threshold points are exceeded $\left(\rho_{1}=-0.619(0.074)\right.$ and $0.754(0.075)$ for regimes 1 and 3 respectively); and near random walk process within the threshold band as rho for this regime $\left(\rho_{0}=-0.066(0.036)\right)$ does not differ significantly from zero. From column two however, the TAR effect has blurred the rapid adjustment phases in the linear representation with 
indication of strong persistence in the inter-markets relation ( $\rho=-0.149(0.017))$. Thus the strength of TAR models in this respect is obvious. In the second half of the table, results from the Markov switching version are presented. Following Krolzig (1997), a three state representation of the b-TAR model in the form of switching mean and adjustment parameters was used (see equations 05-08). In this simple nonlinear data set the Markovian variant (MSIA) also produces similar results and carries same market integration conclusions as the b-TAR model does. For instance two distinct adjustment processes implied by TC motivated rent series from spatially integrated markets are produced. These are $0.799(0.072)$ and $-0.818(0.084))$ for regimes one and three; and $(-0.085(0.017))$ for regime two. For the later regime, price differentials that fell within the threshold band did not adjust back, while strong correction ensued for regimes three and one where price differentials exceeded the TC levels. Again, the intercept terms for regimes one and three differ significantly from zero while that of regime two is not, similar to results from the b-TAR, even though in this particular set the symmetric structure could not be captured as imposed by the DGP.

In line with the main proposition that motivates the application of PBM and limits imposed by data and conceptual complexities on b-TAR models (see Abunyuwah, 2013), we also applied the MSIA and b-TAR models to analyse series $B$. This data set is characterised by a mixture of TC based threshold effects and switching equilibrium conditions implied by alternating segmented and integrated market conditions. The results are presented in Table 2 below.

Table 2: TAR and Markov Estimates of Complex Non-linear Series (Series B)

\begin{tabular}{|c|c|c|c|c|c|c|c|}
\hline & \multirow{3}{*}{$\begin{array}{l}\text { Linear } \\
\text { Model }\end{array}$} & \multicolumn{3}{|c|}{ B-TAR Model } & \multicolumn{3}{|c|}{ Markov Variant (MSIA) } \\
\hline & & $\begin{array}{l}\text { Regime } \\
1\end{array}$ & Regime 2 & Regime 3 & Regime 1 & Regime 2 & $\begin{array}{l}\text { Regime } \\
3\end{array}$ \\
\hline \multicolumn{7}{|l|}{ Variable } & \\
\hline Threshold & & $\mathrm{Rt} \leq-$ & $-7.35 \leq \mathrm{Rt}$ & $\mathrm{Rt} \geq 5.25$ & & & \\
\hline Point & & 7.35 & $\leq 5.25$ & & & & \\
\hline Constant & $\begin{array}{c}0.015 \\
(0.092)\end{array}$ & $\begin{array}{l}-5.603 \\
(0.689)\end{array}$ & $\begin{array}{l}-0.156 \\
(0.064)\end{array}$ & $\begin{array}{l}3.165 \\
(0.385)\end{array}$ & $\begin{array}{l}-4.389 \\
(0.495)\end{array}$ & $\begin{array}{l}0.077 \\
(0.160)\end{array}$ & $\begin{array}{l}0.755 \\
(0.253)\end{array}$ \\
\hline $\mathrm{R}(\mathrm{t}-1)$ & $\begin{array}{l}-0.072 \\
(0.012)\end{array}$ & $\begin{array}{l}-0.340 \\
(0.052)\end{array}$ & $\begin{array}{l}-0.260 \\
(0.013)\end{array}$ & $\begin{array}{l}-0.220 \\
(0.034)\end{array}$ & $\begin{array}{l}-0.745 \\
(0.070)\end{array}$ & $\begin{array}{l}0.052 \\
(0.086)\end{array}$ & $\begin{array}{l}-0.506 \\
(0.087)\end{array}$ \\
\hline \multicolumn{8}{|l|}{ Regime } \\
\hline $\begin{array}{l}\text { Probabiliti } \\
\text { es }\end{array}$ & 1.0000 & 0.100 & 0.710 & 0.190 & 0.197 & 0.474 & 0.321 \\
\hline $\begin{array}{l}\text { LR } \\
\text { (Davies) }\end{array}$ & & \multicolumn{3}{|c|}{$124.831(0.000)^{* * *}$} & \multicolumn{3}{|c|}{$52.972[0.000]^{* * *}$} \\
\hline
\end{tabular}

Source: Own Analysis with MSVAR 3.1: ${ }^{* * * * * * * ;}$ represent significance levels under 1, 5 and $10 \%$

From Table 2, the null of linear representation is also rejected as indicated by the LR and the Davies statistics. When b-TAR model was applied, the three adjustment parameters produced (see columns 3 to 5 of row five of the table) indicate a form of persistence across all the regimes. Unlike the simple nonlinear data set considered in Table 1, the impact of the complex data set has significantly blurred and understated the strong rent correction implied by periods of relatively perfect market integration phases (see Abunyuwah, 2013 for recent demonstration). In the second half of the table, results from the Markov variant are also presented. Although, three statistically different adjustment parameters were produced from Markov version of equation (10): -0.745(0.070); 0.052(0.086) and -0.506(0.087), those of regimes 1 and 3, point to a form of relatively rapid correction while that of regime 2 , like the results from Table one for the simple non-linear data set, indicates strong persistence.

Discussion: The results presented above for series $A$ indicate that both models could identify the adjustment processes into the two regime structures imposed on the DGP. It is worth noting that the intercept values obtained from the Markov variant may erroneously imply asymmetry in rent levels if one attempts to interpret these in terms of a threshold structure. In line with conclusions drawn by Abunyuwah (2013), b-TAR results from series $B$ do not point to strong conclusion for TC-based threshold 
effects where the adjustment parameter $(\rho)$ values for regimes 1 and 3 were expected to be high in absolute terms. Although applying five-state structure in the b-TAR framework brought further insights into the nature of dynamics that associate the system, the fundamental model structure of the TAR which estimates adjustment parameters based on levels of $\mathrm{R}_{\mathrm{t}-1}$ automatically produces biased estimates if the series are characterised by alternating integrated and segmented markets interrelationship. This occurs in that TAR models concentrate out samples based on $\mathrm{R}_{\mathrm{t}-1}$ levels (horizontal strata). Thus, once a threshold point is defined dynamics of series that fall below or above such threshold level form a subsample and are assessed together.

Results from the Markov variants presented in Table 2 and from specification (08) produced adjustment estimates that were closer to those of the true DGP utilised. However, to conclude on whether the periods of strong persistence are due to threshold or segmentation effects from the direct three-state b-TAR version of equation (07) requires further information. That is, multiple equilibria structure evaluated in dynamic framework imposes theoretical limitation on the basic three-state b-TAR and its Markov variant. This is due to the fact that rent levels that associate periods of inter-market segmentation or imperfections are significantly greater or less than zero (price differentials greater than TC in absolute terms) while those that fall within threshold band are not (see Barrett and Li, 2002). In this case an increased number of states are required to further create distinction between persistence due to threshold effects and that of inter-market imperfections or segmentation. If transaction costs levels can be estimated as in PBM applications then the lower level complications imposed by TC based threshold effects can be removed or concentrated out in sample splitting approach as suggested by Abunyuwah (2008) and Van Campenhout (2009). To this effect we applied a five-state regime switching models in both the b-TAR and the Markov frameworks. For the b-TAR model, four and five regime systems were estimated. Information criteria selected the five-state b-TAR structure where in addition to the three threshold points estimated under the classical three-state b-TAR specification (Table 2), two other ones were detected at -3.9 and 3.3. The following model parameter estimates for regime specific constants (Const) and adjustment parameters ( $\left.\mathrm{R}_{\mathrm{t}-1}\right)$ : (Const -4.718(0.151); $\mathrm{R}_{\mathrm{t}-1}-0.877(0.024)$ ) and (Const 3.151(0.383); $\mathrm{R}_{\mathrm{t}-1}-0.220(0.034)$ ) respectively were estimated from the five regime model. Though increased number of states has brought further insights, as has been noted above TAR models concentrate out samples based on $\mathrm{R}_{\mathrm{t}-1}$ levels (horizontal strata), which inherently produce biased adjustment parameter estimates. In the Markov framework, the five-state regime switching model was estimated using equations (06). The following results were produced: (Const 0.102(0.068), $R_{t-1}$ 0.958(0.036); Const -7.135(0.422), $\mathrm{R}_{\mathrm{t}-1}$ 0.754(0.104); Const -3.293(0.363), Rt-1 0.298(0.041); Const 3.905(0.319), $\mathrm{R}_{\mathrm{t}-1}$ 0.199(0.041); Const 4.497(0.358), $\mathrm{R}_{\mathrm{t}-1}$ 0.828(0.137)). In the Markov variant, while the two distinct adjustment processes remained, it has also become obvious that some periods of higher rent levels are also characterised by very low rate of correction (regime 2 and 5) though not as sticky as those in regime one where TC based threshold effects are expected. Unlike the b-TAR structure, the MS-EM is not affected by the mixed adjustment patterns once some sort of state transition persistence exists with the periods of inter-market anomalies as it uses sub-samples extracted in vertical windows.

\section{Conclusion}

In this paper, we have demonstrated that given the flexibility of hidden Markov models and the fact that market equilibrating processes fall within a complex non-linear time series system, Markovian methods can directly be adopted in market integration analysis. The exercise has shown that the Markovian models can conveniently be formulated in equilibrium structure implied b-TAR and PBM conceptualizations. Thus, while this study did not employ formal model selection techniques in assessing how the Markov variants perform against b-TAR models, with our prior knowledge in the DGP and following conceptual/theoretical bases used in MI model applications flexibility and strengths of Markov models in non-linear MI processes have been demonstrated. The alternating dynamic processes and efficiency implications implied by multiple equilibria inter-market structures can be captured by the Markovian variants. Future research should investigate testing issues on asymmetry in rent levels. Also how both threshold dynamics and switching equilibria non-linearities can be contained in the b-TAR structure should be explored (i.e. hierarchical Markov framework).

\section{References}

Abdulai, A. (2002). Using threshold cointegration to estimate asymmetric price transmission in the Swiss Pork market. Applied Economics, 34(6), 679-687 
Abdulai, A. (2007). Spatial and Vertical price transmission in food staples market chains in Eastern and Southern Africa: What is the evidence? Paper presented at the FAO Trade and Markets Division Workshop on Staple Food Trade and Market Policy Options for Promoting Development in Eastern and Southern Africa, Rome, March 1-2, 2007.

Abunyuwah, I. (2008). Market Integration Analysis and Time-series Econometrics- Conceptual Insights from Markov-switching Models. PhD. Thesis, SUB. University of Gottingen, Germany.

Abunyuwah, I. (2012). Modelling and econometric frontiers in market integration and price transmission analysis. Cont. J. Agric Economics, 6(1), 28-39

Abunyuwah, I. (2013). Implications of Conceptual and Data Complexities on Time-Series Econometric Applications in Market Integration Analysis. Studies in Agric Economics, 115(1), 33-38

Amikuzuno, J. (2011). Border Effects on Spatial Price Transmission between Fresh Tomato Markets in Ghana and Burkina-Faso: Any Case for Promoting Trans-border Trade in West Africa? Paper prepared for presentation at the 85th Annual Conference of the Agricultural Economics Society, University of Warwick,UK, 16-18 April 2012.

Balke, N. S. \& Fomby, T. B. (1997). Threshold cointegration. International Economic Review, 38, 627-645.

Barrett, C. B. (2005). Market integration: In The New Palgrave Dictionary of Economics, 2nd edition, ed. Lawrence E. Blume and Steven N. Durlauf, (London: Palgrave Macmillan)

Barrett, C. B. \& Li, J. R. (2002). Distinguishing between equilibrium and integration in spatial price analysis. American Journal of Agricultural Economics, 84, 292-307.

Baulch, B. (1997). Transfer costs, spatial arbitrage, and testing for food market integration. American Journal of Agricultural Economics, 79, 477-487.

Blimes, J. (2006). What HMMs can do. IEICE Transactions in Information and Systems, E89-D (3), 869-891

Brorsen, B. W., Chavas, J. P., Grant, W. R. \& Schnake, L. D. (1985). Marketing margins and price uncertainty: The case of the U.S. Wheat market. American J. Agricultural Economics, 67, 521-28.

Brummer, B., Von Cramon-Taubadel, \& Zorya, S. (2009). The Impact of Market and Policy Instability on Price Transmission between Wheat and Flour in Ukraine. European Review of Agricultural Economics, 36(2), 203-330.

Butler, J. S. \& Moser, C. (2010). Structural Model of Agricultural Markets in Developing Countries. American Journal of Agricultural Economics, 92, 1364-1378.

Cappe', O., Moulines, E. \& Ryden, T. (2005). Inference in Hidden Markov Models. Spinger. New York, USA.

Diebold, F. X., Lee, J. H. \& Weinbach, G. C. (1994). Regime Switching with Time-varying Transition Probabilities. C. Hargreaves (Ed.), Nonstationary time series analysis and cointegration, Oxford University Press, Durham, NC: 283-302.

Enke, S. (1951). Equilibrium among spatially separated markets: solution by electrical analogue. Econometrica, 19, 40-47.

Fackler, P. L. \& Goodwin, B. K. (2001). Spatial price analysis. In B. L. Gardner, \& G.C. Rausser (Eds.), Handbook of Agricultural Economics (pp. 972-1024). Amsterdam: Elsevier Science

Fackler, P. \& Tastan, H. (2008). Estimating the Degree of Market Integration. American Journal of Agricultural Economics, 90, 69-85.

Farrell, M. J. (1952). Irreversible demand functions. Econometrica, 20, 171-186

Filardo, A. J. (1994). Business-Cycle Phases and Their Transitional Dynamics. J. Business and Economic Statistics, 12(3), 299-308.

Goodwin, B. K. \& Piggott, N. E. (2001). Spatial market integration in the presence of threshold effects. American Journal Agricultural Economics, 83, 302-317.

Granger, C. W. J. \& Elliot, C. M. (1967). A Fresh look at wheat prices and markets in the Eighteenth Century. Economic History Review, 20, 257-265

Hamilton, J. D. (1989). A new approach to the economic analysis of nonstationary time series and the business cycle, Econometrica, 57, 357-384.

Hamilton, J. D. \& Susmel, R. (1994). Autoregressive conditional heteroskedasticity and changes in regime. Journal of Econometrics, 64, 307-333.

Kinnucan, H. W. \& Forker, O. D. (1987). Asymmetry in farm to retail price transmission for major dairy products. American Journal of Agricultural Economics, 69, 285-292.

Kim, C. J. (1994). Dynamic linear models with Markov-switching. Journal of Econometrics, 60, 1-22.

Kim, C. J. \& Nelson, C. R. (1999). State-Space Models with Regime Switching, Cambridge, MA: MIT Press.

Kostov, P. \& Lingard, J. (2004). Regime-switching vector error correction model (VECM) analysis of UK meat consumption. Econometrics 0409003, EconWPA

Krolzig, H. M. (1997). Markov Switching Vector Autoregressions. Modelling, Statistical Inference and Application to Business Cycle Analysis. Berlin: Springer. 
Krolzig, H. M. (1998). Econometric modelling of Markov-switching vector autoregressions using MSVAR for Ox. Institute of Economics and Statistics and Nuffield College, Oxford.

Krolzig, H. M., Marcellino, M. \& Mizon, G. E. (2002). A Markov-switching vector equilibrium correction model of the UK Labour market. Empirical Economics, 27(2), 233-254.

Lele, U. (1967). Market integration: a study of sorghum prices in Western India. Journal of Farm Economics, 49, 149-159

McNew, K. \& Fackler, P. L. (1997). Testing market equilibrium: Is cointegration informative? Journal of Agriculture and Resource Economics, 22, 191-207.

Meyer, J. (2004). Measuring market integration in the presence of transaction costs - A threshold vector error correction approach. Agricultural Economics, 31, 327-334

Moser, C., Barrett, C. \& Minten, B. (2009). Spatial integration at multiple scales: Rice markets in Madagascar. Agricultural Economics, 40, 281-294.

Negassa, A. \& Myers, R. (2007). Estimating policy effects on spatial market efficiency: An extension to the parity bounds model. American Journal of Agricultural Economics, 89, 338-352

Otranto, E. (2005). The Multi-chain Markov switching model. Journal of Forecasting, 24, 523-537.

Obstfeld, M. \& Taylor, A. M. (1997). Nonlinear aspects of goods-market arbitrage and adjustment; Heckscher's commodity points revisited. Journal of the Japanese and International Economies, 11, 441-79.

Ravallion, M. (1986). Testing market integration. American Journal of Agricultural Economics, 68(1), 102109.

Tweeten, L. G. \& Quance L. (1969). Positivistic measures of aggregate supply elasticities: some new approaches. American Economic Review, 59, 175-183

Samuelson, P. (1952). Spatial price equilibrium and linear programming. American Economic Review, 42, 283-303.

Sexton, R. J., Kling, C. L. \& Carman, H. F. (1991). Market integration, efficiency of arbitrage, and imperfect competition: methodology and application to U.S. celery. American Journal of Agricultural Economics, 73, 568-80.

Spiller, P. T. \& Wood, R. O. (1988). The estimation of transactions costs in arbitrage models, Journal of Econometrics, 39, 309-326.

Stephens, E. C., Mabaya, E., von Cramon-Taubadel, S. \& Barrett, C. B. (2008). Spatial Price Adjustment with and without Trade. Selected Paper prepared for presentation at the American Agricultural Economics Association Annual Meeting, Orlando, FL, July 27-29, 2008.

Takayama, T. \& Judge, G. (1971). Spatial and Temporal Price Allocation Models. North-Holland Pub. Co., Amsterdam

Van Campenhout, B. (2007). Modeling trends in food market integration: Method and application to Tanzanian maize markets. Food Policy, 32, 112-127.

Van Campenhout, B. (2009). Sample splitting and threshold estimation techniques. Applications in development studies. Open Access publications from Katholieke Universiteit Leuven urn:hdl:123456789/244590, Katholieke Universiteit Leuven

von Cramon-Taubadel, S. (1998). Estimating asymmetric price transmission with the error correction representation: an application to the German pork market. European Review of Agricultural Economics, 25, 1-18.

Wohlgenant, M. K. (1999). Product heterogeneity and the relationship between retail and farm prices. European Review of Agricultural Economics, 26, 219-227

Zhao, J., Goodwin, B. K. \& Pelletier, D. (2012). A New Approach to Investigate Market Integration: a Markov-Switching Autoregressive Model with Time-Varying Transition Probabilities. Selected Paper prepared for presentation at the Agricultural \& Applied Economics Association's 2012 AAEA Annual Meeting, Seattle, Washington, August 12 14, 2012 